\title{
Using the Bergman-Paris Question to screen seniors in the emergency department
}

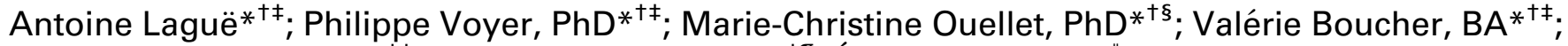 \\ Marianne Giroux, MSc* ${ }^{* \ddagger}$; Mathieu Pelletier, $\mathrm{MD}^{\dagger \pi}$; Émilie Gouin, MD; Raoul Daoust, MD, MSc**; \\ Simon Berthelot, $\mathrm{MD}^{*+}$; Michèle Morin, MD, MSc ${ }^{* \neq}$; Thien Tuong Minh Vu, $\mathrm{MD}^{\dagger+\neq \ddagger \S}$;

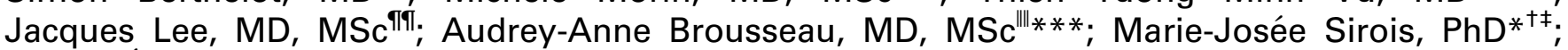 \\ Marcel Émond, MD, MSc* ${ }^{\dagger \ddagger}$
}

\section{ABSTRACT}

Objectives: In the fast pace of the Emergency Department (ED), clinicians are in need of tailored screening tools to detect seniors who are at risk of adverse outcomes. We aimed to explore the usefulness of the Bergman-Paris Question (BPQ) to expose potential undetected geriatric syndromes in community-living seniors presenting to the ED.

Methods: This is a planned sub-study of the INDEED multicentre prospective cohort study, including independent or semi-independent seniors ( $\geq 65$ years old) admitted to hospital after an ED stay $\geq 8$ hours and who were not delirious. Patients were assessed using validated screening tests for 3 geriatric syndromes: cognitive and functional impairment, and frailty. The BPO was asked upon availability of a relative at enrolment. BPQ's sensitivity and specificity analyses were used to ascertain outcomes.

Results: A response to the BPQ was available for 171 patients ( $47 \%$ of the main study's cohort). Of this number, $75.4 \%$ were positive (suggesting impairment), and $24.6 \%$ were negative. To detect one of the three geriatric syndromes, the BPQ had a sensitivity of $85.4 \%(95 \% \mathrm{Cl}[76.3,92.0])$ and a specificity of $35.4 \%(95 \% \mathrm{Cl}[25.1,46.7])$. Similar results were obtained for each separate outcome. Odds ratio demonstrated a higher risk of presence of geriatric syndromes.

Conclusion: The Bergman-Paris Question could be an ED screening tool for possible geriatric syndrome. A positive BPO should prompt the need of further investigations and a negative BPQ possibly warrants no further action. More research is needed to validate the usefulness of the BPQ for day-to-day geriatric screening by ED professionals or geriatricians.

\section{RÉSUMÉ}

Objectif: Au département d'urgence (DU), les médecins ont besoin d'outils adaptés pour effectuer une évaluation rapide des patients âgés. L'objectif principal de cette étude est d'évaluer l'utilité de la Question de Bergman-Paris (QBP) pour détecter des grands syndromes gériatriques (troubles cognitifs, atteinte fonctionnelle et fragilité) chez les personnes âgées au DU.

Méthode: Cette sous-étude fait partie de l'étude multicentrique prospective MIDI-INDEED. Les patients inclus devaient être âgés de 65 ans et plus, être autonomes ou semiautonomes, être à l'urgence pendant $\geq 8 \mathrm{~h}$ et ne pas avoir développé de délirium durant cette période au DU en plus d'être admis. Des outils validés ont été utilisés pour évaluer les troubles cognitifs, l'atteinte fonctionnelle et la fragilité. La QBP était demandée à un proche lors du séjour du patient au DU ou à l'étage. Des analyses de sensibilité et de spécificité pour la QBP ont été calculées.

Résultats: 171 réponses à la QBP sont disponibles représentant $47 \%$ de la cohorte de l'étude principale dont $75,4 \%$ avec une QBP positive et $24,6 \%$ négative. La QBP a une sensibilité de $85,4 \%(95 \%$ IC $[76,3-92,0])$ et une spécificité de $35,4 \%(95 \%$ IC $[25,1-46,7])$ pour détecter au moins un des trois syndromes gériatriques majeurs. Le risque d'avoir un syndrome gériatrique est plus grand chez les personnes avec une QBP positive que ceux avec le test négatif.

Conclusion: La QBP pourrait être un outil intéressant pour dépister les syndromes gériatriques à l'urgence. Les personnes avec une QBP négative ne nécessiteraient pas d'investigations supplémentaires tandis que ceux avec une QBP positive seraient à évaluer. Une étude subséquente

From the *Axe Santé des populations et pratiques optimales en santé, CHU de Québec Hôpital de l'Enfant-Jésus, Québec, QC; †Université Laval, Québec, QC; ¥Centre d’Excellence sur le Vieillissement de Québec, Québec, QC; §Centre Interdisciplinaire de Recherche en Réadaptation et Intégration Sociale, Québec, OC; ๆCentre Intégré de Santé et de Services Sociaux de Lanaudière, Joliette, OC; ॥Centre Hospitalier Régional de Trois-Rivières, Trois-Rivières, QC; **Centre de recherche de I'Hôpital du Sacré-Cœur de Montréal, Montréal, QC; ††Centre de recherche du Centre hospitalier de I'Université de Montréal, Montréal, OC; $¥ \ddagger$ Centre hospitalier de I'Université de Montréal, Montréal, QC; §§Institut de gériatrie de I'Université de Montréal, Montréal, QC; TाSunnybrook Health Sciences Centre, Toronto, ON; IIIDepartment of Family and Community Medicine, University of Toronto, Toronto, ON; and the ***Schwartz-Reisman Emergency Medicine Institute, Mount Sinai Hospital, Toronto, ON.

Correspondence to: Dr. Marcel Émond, CHU de Québec - Hôpital de I'Enfant-Jésus, 1401, 18 e rue, H-608, Québec, QC, G1J 1Z4; Email: marcelemond1@me.com 
serait nécessaire pour valider l'implantation clinique de la question pour le personnel de l'urgence. $\overline{\text { Keywords: geriatric syndromes, frailty, cognitive impairment, }}$ functional impairment, seniors

\section{INTRODUCTION}

The number of visits by seniors to emergency departments (ED) has increased by $30 \%$ in recent years, ${ }^{1}$ a population that needs more attention from ED health professionals, especially those who are frail. ${ }^{2}$ Frailty is characterized by multi-systemic dysfunction associated with abnormal aging. It is linked to an increased risk of adverse outcomes and can be related to cognitive impairment, ${ }^{3}$ which may affect patients' ability to perform daily activities. ${ }^{4}$ Moreover, seniors with undetected $\operatorname{cog}$ nitive impairment are at higher risk of an unplanned return to the ED within 6 months of their discharge. ${ }^{5}$ Cognitive and functional impairment, frailty, and delirium are all elements of "the geriatric syndrome" that also includes falls, incontinence, or immobility. ${ }^{6}$

The numerous benefits of adapting a medical approach to the specific needs of seniors were recently underlined by the Acute Care for Elders (ACE) strategy. ${ }^{7}$ In 2014, the American College of Emergency Physicians (ACEP) published new practice guidelines, also endorsed by the Canadian Association of Emergency Physicians (CAEP), suggesting that ED professionals should be trained to screen seniors for cognitive and functional impairment and delirium. ${ }^{8}$ Those guidelines suggest that a visit to the ED is an opportunity to detect these often undiagnosed elements of the geriatric syndrome and to refer patients to the appropriate resources during their hospitalization or after their discharge. ${ }^{9}$

ED-friendly tools must be developed to better fit the fast-paced ED environment. ${ }^{4}$ The Bergman-Paris Question (BPQ) is a one-question screening test that was developed by Dr. Howard Bergman and involves asking a patient's close relative if they would feel comfortable leaving the patient home alone for three months if other members of the family were also away. Caporuscio et al. have reported that this single question could detect the presence of dementia in patients followed in a memory clinic. ${ }^{10}$ To our knowledge, no other study has evaluated the BPQ.

The objective of this study was to assess the BPQ as a screening tool for three geriatric syndromes in independent or semi-independent seniors in the ED. Specifically, we sought to explore the predictive capacities of the BPQ for cognitive and functional impairments, as well as frailty.

\section{METHODS}

\section{Study design and setting}

The prospective assessment of the BPQ was a planned substudy of the incidence and impact measurement of delirium induced by ED stay (INDEED) multicentre study. This prospective observational cohort study enrolled patients in four Canadian EDs (Hôpital de l'Enfant-Jésus [Québec City], Hôpital du Sacré-Cœur [Montréal], Centre Hospitalier Affilié Universitaire Régional [Trois-Rivières], and Centre Hospitalier Régional de Lanaudière [Joliette]) between March and July 2015.

\section{Selection of participants}

Patients were included if they: 1 ) were aged $\geq 65$ years; 2) were independent or semi-independent (can perform five of the seven activities of daily living without any help); 3) spent $\geq 8$ hours in the ED; and 4) were admitted to any hospital ward. Patients were excluded if they: 1) were living in a long-term care facility; 2) were unable to consent; 3 ) were unable to communicate in French or English; 4) were experiencing an unstable medical condition leading to their admission to the intensive care unit (ICU); 5) had a previous diagnosis of severe dementia or any other psychiatric condition; or 6) had delirium during their eight-hour ED stay.

\section{Procedure}

Potentially eligible patients were identified using the hospital or ED information system patient tracking software. After an ED stay of more than or equal to eight hours, trained research assistants (RA) obtained 
consent and assessed patients for eligibility directly in the ED when admission was confirmed. Sociodemographic data, medications, and information regarding the patient's comorbidities were also collected. The Charlson index was used to assess comorbidities, ${ }^{11}$ and the Acute Physiology and Chronic Health Evaluation II (APACHE II) was used to evaluate the physiological status upon ED admission. ${ }^{12}$ An available relative was asked the BPQ after the assessment. Close relatives who were not seen in person were contacted by phone with the patient's authorization soon after enrolment. RAs assessed participants' cognitive, functional, and frailty status and also screened for delirium during the initial interview. The latter was also assessed twice a day during the patients' whole ED stay and up to 24 hours after their ward admission, with a minimum of six hours between each evaluation. The study was approved by the Research Ethics Board of the CHU de Québec.

\section{Outcome and measurement}

A trained RA asked patients' relatives the BPQ: "Would you be comfortable leaving your family member home alone for three months if you had to go on a trip to Paris and no other family member or close friend was available?" An answer such as "No, I would not be comfortable" represents a "positive BPQ," suggesting that the patient may have an underlying geriatric syndrome. In contrast, a "Yes" from the patient's relative indicated a "negative BPQ" and may lead to the conclusion that this patient would not benefit from further geriatric assessment.

Cognitive status was assessed using the Telephone Interview for Cognitive Status-modified (TICS-m). ${ }^{13}$ This test can be administrated in person or by telephone and evaluates orientation, attention, language, and memory. Scores range between 0 (worst) and 50/50 (best). ${ }^{14}$ In this study, we determined that a score of $\leq 27 / 50$ with adjustment for education suggested cognitive impairment. ${ }^{13}$

Functional status was assessed using the validated Older Americans Resources and Services scale (OARS). ${ }^{15,16}$ Patients answered based on how they usually performed their daily activities before their ED visit. Scores range from 0 (dependent) to $28 / 28$ (completely independent). A two-point decrease represents complete loss of independence for one activity of daily living or partial dependence for two activities of daily living. ${ }^{17}$ This test is usually used to detect a potential functional decline. In this study, we used this test as an image of our participants' functional status. With no specific guideline available in the literature, our steering committee decided that a score of $<26$ would suggest a clinically significant functional impairment.

Frailty status was evaluated using the Clinical Frailty Scale (CFS). ${ }^{3}$ This scale is based on category descriptors ranging from 1 to 7 (1, very fit; 2, well; 3, managing well with controlled medical problems; 4, vulnerable; 5, mildly frail; 6 , moderately frail; and 7 , severely frail). ${ }^{3}$ In our study, patients with a score of $1,2,3$, or 4 were considered robust. In contrast, patients with scores of 5,6 , or 7 were classified as frail. ${ }^{3,18}$ A revised CFS scale adds scores 8 and 9 representing very severely frail and terminally ill patients. As our participants were all independent or semi-independent, these two categories were deemed unnecessary for this study.

Delirium was assessed using the Confusion Assessment Method (CAM), a validated measure with excellent sensitivity (94\% to $100 \%)$ and specificity $(90 \%$ to $100 \%) .{ }^{19,20}$ The CAM assesses the following: acute onset and fluctuation, inattention, disorganized thinking, altered level of consciousness, disorientation, memory impairment, perceptual disturbance, abnormal psychomotor activity, and altered sleep-wake cycle.

\section{Analyses}

Descriptive analyses were conducted for sociodemographic, clinical, and outcome variables, which were compared according to the BPQ response (Fisher test and $t$-tests for categorical and continuous variables, respectively). The Kolmogorov-Smirnov test was used to compare the distribution of outcomes variables with the BPQ response. Raw sensitivity and specificity of the BPQ for the four outcomes and its positive and negative predictive values were estimated with their exact binomial $95 \%$ confidence interval $(95 \% \mathrm{CI}) .{ }^{21}$ Crude and adjusted (age and sex) areas under the receiver operating curve (AUC) were also computed with 95\% CIs and obtained through a logistic regression. ${ }^{22}$ The risk of presenting outcomes if the BPQ was negative was estimated using an odds ratio (OR) with a logistic regression. ${ }^{22}$ All analyses were completed with 
Statistical Analysis System software (SAS Institute, Cary, NC, version 9.4).

\section{RESULTS}

\section{Participant's characteristics}

Of the 367 patients recruited in the INDEED study, 171 (47\%) had a relative who answered the BPQ. There were no significant differences in sociodemographic data between patients for whom a BPQ answer was available and those without an answer. Patients' characteristics were similar among the four centres. Table 1 details the participants' characteristics. The BPQ was positive for $75 \%$ of the patients, indicating that most relatives were not comfortable leaving the participants home alone for three months. Patients with a positive BPQ were older $(p=0.048)$. No significant differences in sex $(p=0.21)$, living environment $(p=0.21)$, or marital status $(p=0.59)$ were found between patients with a "Yes" or "No" answer to the BPQ.

\section{BPQ screening capacity}

To detect one of the three outcomes minimally, the BPQ had a sensitivity of $85.4 \%$ (95\% CI 76.3-92.0), specificity of $35.4 \%$ (95\% CI 25.1-46.7), positive predictive value (PPV) of $58.9 \%$ (95\% CI 49.9-67.5), and negative predictive value (NPV) of $69.0 \%$ (95\% CI 52.9-82.4). Incident delirium has not been included because this condition is a further consequence, and the BPQ was asked at the initial interview. Specifically, the predictive capacities of the BPQ for each outcome variables are reported in Table 2 . The OR for a patient with a positive BPQ presenting with one of the three geriatric syndromes was 3.2 (95\% CI 1.5-6.7), as compared with those with a negative BPQ.

\section{Cognitive impairment}

The BPQ had a sensitivity of $86.5 \%$ (95\% CI 71.295.5) to detect cognitive impairment with a specificity of $27.8 \%$ (95\% CI 20.4-36.3), a PPV of $25.0 \%$

\begin{tabular}{|c|c|c|c|c|}
\hline \multirow[b]{2}{*}{ Characteristics } & \multicolumn{2}{|c|}{ Answer to the BPQ } & \multirow[b]{2}{*}{ Total $(N=171)$} & \multirow[b]{2}{*}{$p$-value } \\
\hline & Yes $(n=42)$ & No $(n=129)$ & & \\
\hline Age (SD) & $74.7(6.8)$ & $77.6(8.6)$ & $76.9(8.3)$ & 0.05 \\
\hline Men (\%) & $24(57)$ & $58(45)$ & $82(48)$ & 0.21 \\
\hline Spouse/married (\%) & $27(64)$ & $76(59)$ & $103(60)$ & 0.59 \\
\hline Living alone in their home (\%) & $9(22)^{\ddagger}$ & $17(13)$ & $26(15)$ & 0.21 \\
\hline Hospital stay in the last three months* $(\%)$ & $18(43)$ & $53(41)$ & $71(42)$ & 0.86 \\
\hline Receiving home health care services (\%) & $5(12)$ & $31(24)$ & $36(21)$ & 0.13 \\
\hline Previous use of a transitional care centre ${ }^{\dagger}$ in the last three months (\%) & $1(1)$ & $11(9)$ & $12(9)$ & 0.45 \\
\hline Mean Charlson index score (SD) & $1.76(1.90)$ & $2.67(2.24)$ & $2.45(2.19)$ & \\
\hline Mean Apache score (SD) & $7.74(3.19)$ & $6.98(3.48)^{\S}$ & $7.17(3.42)$ & \\
\hline Mean TICS-m score adjusted for education (SD) & $32.3(5.0)$ & $31.6(5.8)^{n}$ & $31.8(5.4)$ & 0.43 \\
\hline Mean OARS score (SD) & $27.1(1.3)$ & $25.8(2.3)$ & $26.2(2.2)$ & $<0.001$ \\
\hline $\mathrm{ADL}(\mathrm{SD})$ & $13.8(0.5)$ & $13.4(0.8)$ & $13.5(0.7)$ & \\
\hline AIDL (SD) & $13.3(1.1)$ & $12.4(1.8)$ & $12.6(1.7)$ & \\
\hline Mean CFS score (SD) & $2.9(1.0)^{\|}$ & $3.8(1.1)^{\|}$ & $3.6(1.2)$ & $<0.001$ \\
\hline No. of patients with cognitive impairment (TICS-m $\leq 27)(\%)$ & $5(12)$ & $32(25)$ & $37(22)$ & \\
\hline No. of patients with functional impairment (OARS < 26) (\%) & $9(21)$ & $65(50)$ & $74(43)$ & \\
\hline No. of frail patients (CFS $\geq 5$ ) (\%) & $2(5)$ & $32(25)$ & $34(20)$ & \\
\hline No. of patients with minimally one of the three conditions above (\%) & $13(31)$ & $76(59)$ & $89(52)$ & \\
\hline No. of patients with delirium induced by ED stay (\%) & $1(2)$ & $19(15)$ & $20(12)$ & \\
\hline History of dementia & 0 & 3 & 3 & \\
\hline \multicolumn{5}{|c|}{$\begin{array}{l}\text { ADL = activities of daily living; } C F S=\text { Clinical Frailty Scale; IADL= instrumental activities of daily living; OARS = Older Americans Resources and Services; TICS-m= The modified Telephone } \\
\text { Interview for Cognitive Status. } \\
\text { "Visit ED, day surgery, or hospitalization. } \\
\text { †Either rehabilitation centre, day hospital, or convalescence centre. } \\
\text { fOne living environment missing. } \\
\text { \$T Two data missing. } \\
\text { "One education missing. } \\
\text { "One score missing. }\end{array}$} \\
\hline
\end{tabular}



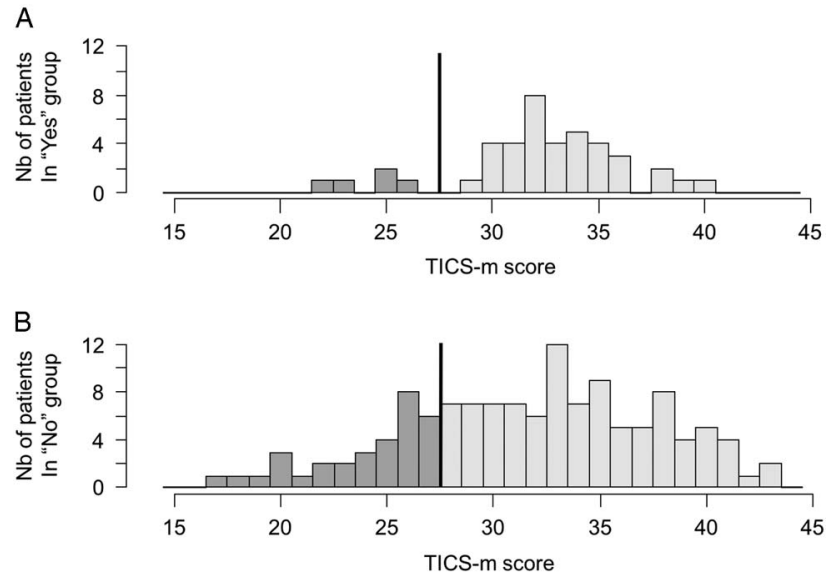

Figure 1. Distributions of TICS-m values according to a negative (A) or positive (B) BPQ. The line illustrates the cut-off score of $\leq 27 / 50$; the darker tone represents patients with possible cognitive impairments.

(95\% CI 17.8-33.4), and an NPV of $88.1 \%$ (95\% CI 74.4-96.0). The distribution of TICS-m scores according to the relative's response to the BPQ is shown in Figure 1. Because of the small sample size, they were not significantly different $(p=0.10)$. However, in the negative BPQ group, the majority of patients were above the cut-off of 27/50 (Figure 1A), and the positive BPQ group had a heterogeneous distribution (Figure 1B). The TICS-m mean scores were neither statistically nor clinically significant between the yes and no groups $(p=0.43)$.

The OR for patients with a positive BPQ presenting with cognitive impairment was 2.5 (95\% CI 0.9-6.8), as compared with those with a negative BPQ. However, approximately one-eighth of the patients with cognitive impairment remain unrecognized. Of note, three participants in our cohort had a past history of mild dementia. All three had a negative BPQ.

\section{Functional impairment}

Patients with functional impairment were efficiently detected using the BPQ with a sensitivity of $87.8 \%$ (95\% CI 78.2-94.3), a specificity of $34 \%$ (95\% CI 24.7-44.3), an NPV of 78.6\% (95\% CI 63.2-89.7), and a PPV of $50.4 \%$ (95\% CI 41.5-59.3). Likewise, there were significant differences in mean OARS scores between seniors with a negative BPQ (mean $[M]=27.1$, standard deviation $[\mathrm{SD}]=1.3)$ and those with a positive BPQ $(M=25.8, \mathrm{SD}=2.3) \quad(p<0.001)$. As shown in Figure $2 \mathrm{~A}$ and $2 \mathrm{~B}, 78 \%$ of patients with a negative $\mathrm{BPQ}$ were independent in their daily life (OARS score from 

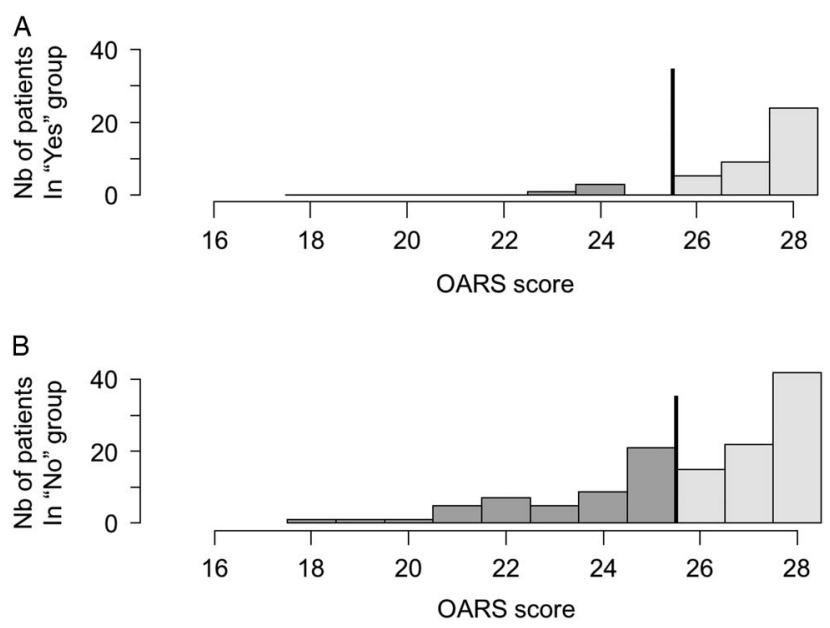

Figure 2. Distributions of OARS values according to a negative (A) or positive (B) BPO. The line illustrates the cutoff score of $<26 / 28$; the darker tone represents patients with possible functional impairments.

26 to $28 / 28)$, v. $48 \%$ if the BPQ was positive $(p=0.009)$. The OR for patients with a positive BPQ presenting with functional impairment was 3.7 (95\% CI 1.7-8.4), as compared with a negative BPQ.

\section{Frailty}

The BPQ detected almost all frail patients with a sensitivity of $94.1 \%$ (95\% CI 80.3-99.3) but with a specificity of $28.9 \%$ (95\% CI 21.4-37.3). People with a negative BPQ were almost all independent according to the NPV of $95.1 \%$ (95\% CI -83.599.4). However, the BPQ had a PPV of 25.0\% (95\% CI 17.8-33.4) for frailty. Patients with a negative BPQ were more robust than those with a positive answer to the question $(M=2.9, \mathrm{SD} 1.0$ v. $M=3.8$, SD 1.1 , respectively, $p<0.001)$. The distributions of frail patients across a negative and positive BPQ were significantly different $(p=0.003)$ (Figure 3). The OR for being frail if the BPQ was positive was 6.5 (95\% CI 1.5-28.6), as compared with a negative BPQ.

\section{Incident delirium}

A total of 19 of the 20 patients with an episode of incident delirium were detected by the BPQ leading to a sensitivity of $95.0 \%$ (95\% CI 75.1-99.9]) and specificity of $27.2 \%$ (95\% CI 20.2-35.0) (Table 2). From the 20 patients with delirium induced by an extended ED stay, only four were cognitively normal at the initial interview.
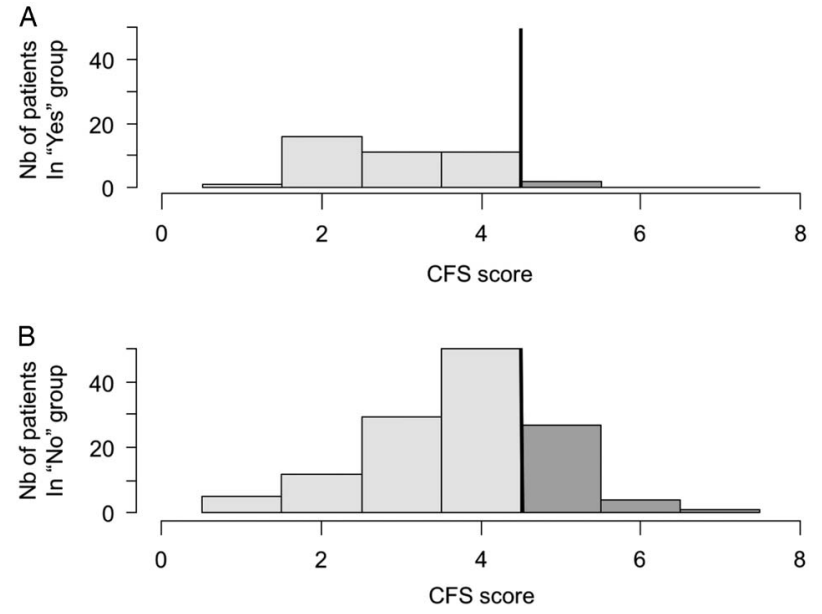

Figure 3. Distribution of CFS values according to a negative (A) or positive (B) BPQ. The line illustrates the cut-off score of $<4 / 7$; the darker tone represents possible frail seniors.

\section{DISCUSSION}

\section{Key results}

The BPQ had good sensitivity but a low specificity $f$ or detecting the three geriatric syndromes in our prospective cohort. Regarding cognitive impairment, our sensitivity result $(86.5 \%)$ was similar to that of Caporuscio et al., ${ }^{10}$ but our specificity dropped significantly $(27.8 \%)$ in our general ED population. They had a sensitivity of $95 \%$ (95\% CI 82.9-99.2) and specificity of $63 \%$ (95\% CI 40.8-80.4) for the diagnosis of dementia in a memory clinic, with a PPV of $0.820(95 \%$ CI $0.681-0.910)$ and an NPV of 0.882 (95\% CI $0.623-0.979)$. This could be explained by differences in our methodologies and populations. Their study was conducted in an outpatient clinic comprising patients with a higher prevalence of cognitive impairment than those in our study. Their study focused on dementia, but we broadened the aim of the study to expose four major geriatric syndromes. Furthermore, the diagnosis of cognitive impairment was completed by a geriatrician or neurologist comparatively to a screening tool (the TICS-m) in our study.

People with a negative BPQ were mostly independent and robust. These results suggest that these people are less likely to need further investigation for any geriatric syndrome. Logically, dependent patients with a lot of comorbidities will not be left alone by their relatives. Cognitive impairment, functional status, frailty, and delirium are all concepts linked together and 
regrouped as a geriatric syndrome. Unsurprisingly, our results demonstrate a link between these notions.

\section{Clinical usefulness of the BPQ}

In the ED, cognitive impairment detection is still not systematically done in day-to-day practice ${ }^{10,23}$ possibly because of the important time and resource constraints in the ED. To address this gap, many validated tests are available, but they are lengthy. For example, the Mini Mental State Examination (MMSE) has a duration of approximately 10 minutes; even if it seems to be short, it can be excessive in the time-pressured ED environment. ${ }^{24}$ Some shorter tests such as the Brief Alzheimer's Screen, Short Blessed Test, or Ottawa 3DY could be interesting alternatives, but all of these have a low specificity despite their high sensitivity. ${ }^{25}$

The BPQ could be seen as a "red flag" to help emergency physicians focus on seniors more at risk. If a patient seems to be functional but has a positive screen per the BPQ, some explanation and further evaluation are probably required depending on the reason given as to the underlying problem.

What is making the BPQ more interesting than these other tests is the evaluation by a family member. Most geriatric patients come to the $\mathrm{ED}$ with a relative. Those relatives are a precious resource to an emergency physician or another health professional to obtain a good portrait of the patient's status and to add information if necessary. ${ }^{26}$

Despite its low specificity, its good sensitivity for geriatric syndromes may make the BPQ a good rapid frontline screening tool for ED professionals. The good NPV (79\% to $98 \%$ ) suggests that patients with a negative BPQ may not need further geriatric syndrome evaluation.

\section{LIMITATIONS}

There are limitations in this study. The presence of the patients at the moment when the BPQ was asked may have biased the relatives' answer because the relatives may have been uncomfortable answering "No." Conversely, most patients visiting EDs have an acute issue, and it probably overestimated the "No" results because of the anxiety and emotional involvement of family members regarding the actual condition.

Our point of reference to detect cognitive impairment was the TICS-m. This test is not the best tool to diagnose mild cognitive impairment or dementia. ${ }^{27}$ The choice of this tool and, moreover, uncertainty regarding the optimal cut-off could have led to the over- or underdiagnosis of cognitive impairment. With the high proportion of patients with a positive TICS-m in our population, a larger number of "No" responses to the BPQ would be expected. The same issues were experienced with the OARS scale cut-off. No study has fixed a score for patients with functional impairment. Currently available literature suggests a loss of two points indicates a functional decline, but our study was cross-sectional for functional status. Because our patients were relatively independent, we used this cut-off even if it may have overestimated the number of impaired seniors.

The response rate for the BPQ was $47 \%$. The high rate of missing data is mostly because of the ED environment in which visitors are not always allowed for extended periods of time. As our patients were independent or semi-independent, not all of them were accompanied by a family member. Some patients also did not allow us to contact their family members for various personal reasons that were not obtained. However, potential selection bias has been rejected because no differences were found in patient characteristics between those who did and those who did not answer the BPQ. Finally, the inclusion and exclusion criteria may have reduced the prevalence of cognitive impairment. Because of the framework of the larger INDEED study, our study participants were independent or semi-independent, and all of them were admitted that is not representative of the general geriatric ED population.

A receiver operating characteristic (ROC) model adjusted for age and sex is better than the BPQ alone for cognitive impairment, functional status, and delirium. For frailty, the AUC for the BPQ alone is the same as the fitted model. Age is a confounding factor that is significantly associated with the BPQ.

\section{In the future}

This ED-tailored screening tool could be helpful in the overcrowded ED to determine which admitted patient should not have any further evaluation because patients with a negative BPQ have been identified as unimpaired and robust. The results of this study coincide with our primary hypothesis that the BPQ may have the ability to screen patients for major geriatric syndromes. We must not forget that the BPQ is only a screening test that can help the emergency physician in obtaining a second opinion from a person who knows the patient better. The usefulness of the BPQ for discharged 
patients should be assessed, and the question should be validated in all ED patients in future studies. Such validation could meet the need of emergency physicians to ensure that elderly patients can safely be discharged home. More investigations will be needed to determine the placement of the BPQ in the toolbox of emergency health professionals.

Acknowledgements: We would like to thank Pierre-Hugues Carmichael for performing the statistical analyses and all the RAs who participated in the recruitment of patients for this study. MÉ had full access to all data in the study and takes responsibility for the integrity of the data and the accuracy of the data analysis. He was responsible for the design, funding, and conduct of the study. $\mathrm{AL}$ led the analyses and wrote the manuscript. MJS, MCO, and MG were involved in the statistical analysis and data interpretation. MP, RD, EG, and ME were responsible for recruitment at all four sites. SB, MM, TTMV, JL, MR, and LJ are all collaborators of the INDEED project. VB managed the study and reviewed the manuscript. AAB, SB, MP, TTMV, VB, MG, MCO, MJS, PV, RD, and ME reviewed and approve the manuscript.

Competing interest: This study was funded by the Fonds de Recherche en Santé du Québec (FQRS 29307). A. Laguë holds a student salary award from the Canadian Frailty Network. Sponsor's role: none.

\section{REFERENCES}

1. Le Commissaire à la santé et au bien-être (CSBE). Les Urgences au Québec: Évolution de 2003-2004 à 2012-2013; 2014. Available at: http://www.csbe.gouv.qc.ca/fileadmin/ www/2014/Urgences/CSBE_Rapport_Urgences_2014.pdf.

2. MSSS. Approche adaptée à la personne agée en milieu hospitalier; 2011. Available at: http://publications.msss.gouv. qc.ca/msss/fichiers/2010/10-830-03.pdf.

3. Rockwood K, Song X, MacKnight C, Bergman H, Hogan DB, $\mathrm{McDowell} \mathrm{I}$, et al. A global clinical measure of fitness and frailty in elderly people. CMA7 2005;173(5):489-95.

4. Lin JS, O'Connor E, Rossom RC, et al. U.S. Preventive Services Task Force Evidence Syntheses, formerly Systematic Evidence Reviews. Screening for Cognitive Impairment in Older Adults: An Evidence Update for the US Preventive Services Task Force. Rockville, MD: Agency for Healthcare Research and Quality; 2013.

5. Lee J, Sirois MJ, Moore L, et al. Return to the ED and hospitalisation following minor injuries among older persons treated in the emergency department: predictors among independent seniors within 6 months. Age Ageing 2015;44(4):624-9.

6. Inouye SK, Studenski S, Tinetti ME, Kuchel GA. Geriatric syndromes: clinical, research, policy implications of a core geriatric concept. 7 Am Geriatr Soc 2007;55(5):780-91.

7. Canadian Foundation for Healthcare Improvement (CFHI), Canadian Frailty Network (CFN). Acute Care for Elders
(ACE) 12-month quality improvement collaborative - Prospectus (Contract No 1); 2016. Available at: http://www. fcass-cfhi.ca/WhatWeDo/ace.

8. American College of Emergency Physicians, American Geriatrics Society, Emergency Nurses Association, Society for Academic Emergency Medicine, Geriatric Emergency Department Guidelines Task Force. Geriatric emergency department guidelines. Ann Emerg Med 2014;63(5):e7-25.

9. Bernstein E. Repeat visits by elder emergency department patients: sentinel events. Acad Emerg Med 1997;4(6):538-9.

10. Caporuscio C, Monette J, Gold S, Monette M, O'Rourke K. Ability of the "Bergman-Paris" Question to Detect Dementia in Community-Dwelling Older People. Can Geriatr 7 2009;12(3):101-3.

11. Rozzini R, Sabatini T, Barbisoni P, Trabucchi M. How to measure comorbidity in elderly persons. 7 Clin Epidemiol 2004;57(3):321-2.

12. Knaus WA, Draper EA, Wagner DP, Zimmerman JE. APACHE II: a severity of disease classification system. Crit Care Med 1985;13(10):818-29.

13. Knopman DS, Roberts RO, Geda YE, Pankratz VS, Christianson TJ, Petersen RC, et al. Validation of the telephone interview for cognitive status-modified in subjects with normal cognition, mild cognitive impairment, or dementia. Neuroepidemiology 2010;34(1):34-42.

14. Duff K, Tometich D, Dennett K. The Modified Telephone Interview for Cognitive Status is More Predictive of Memory Abilities Than the Mini-Mental State Examination. 7 Geriatr Psychiatry Neurol 2015;28(3):193-7.

15. Fillenbaum GG, Smyer MA. The development, validity, and reliability of the OARS multidimensional functional assessment questionnaire. 7 Gerontol 1981;36(4):428-34.

16. Haywood KL, Garratt AM, Fitzpatrick R. Older people specific health status and quality of life: a structured review of selfassessed instruments. $\mathcal{F}$ Eval Clin Pract 2005;11(4):315-27.

17. Sirois MJ, Émond M, Ouellet MC, et al. Cumulative incidence of functional decline after minor injuries in previously independent older Canadian individuals in the emergency department. 7 Am Geriatr Soc 2013;61(10):1661-8.

18. Kahlon S, Pederson J, Majumdar SR, Belga S, Lau D, Fradette $M$, et al. Association between frailty and 30-day outcomes after discharge from hospital. CMAJ 2015;187 (11):799-804.

19. Inouye SK, van Dyck CH, Alessi CA, Balkin S, Siegal AP, Horwitz RI. Clarifying confusion: the confusion assessment method. A new method for detection of delirium. Ann Intern Med 1990;113(12):941-8.

20. Monette J, Galbaud du Fort G, et al. Evaluation of the Confusion Assessment Method (CAM) as a screening tool for delirium in the emergency room. Gen Hosp Psych 2001;23(1):20-5.

21. Bishop YM, Fienberg SE, Holland PW. Discrete multivariate analysis: theory and practice. Springer Science \& Business Media; 2007.

22. Hosmer DW Jr, Lemeshow S, Sturdivant RX. Applied logistic regression. Hoboken: John Wiley \& Sons; 2013.

23. Parke B, Beaith A, Slater L, Clarke AM. Contextual factors influencing success or failure of emergency department interventions for cognitively impaired older people: a scoping and integrative review. 7 Adv Nurs 2011;67(7):1426-48. 
24. Cullen B, O’Neill B, Evans JJ, Coen RF, Lawlor BA. A review of screening tests for cognitive impairment. 7 Neurol Neurosurg Psychiatry 2007;78(8):790-9.

25. Carpenter CR, Bassett ER, Fischer GM, et al. Four sensitive screening tools to detect cognitive dysfunction in geriatric emergency department patients: brief Alzheimer's Screen, Short Blessed Test, Ottawa 3DY, and the caregivercompleted AD8. Acad Emerg Med 2011;18(4):374-84.
26. Goldstein J, Travers A, Hubbard R, Moorhouse P, Andrew MK, Rockwood K. Assessment of older adults by emergency medical services: methodology and feasibility of a care partner Comprehensive Geriatric Assessment (CP-CGA). CFEM 2014;16(5):370-7.

27. Herr M, Ankri J. A critical review of the use of telephone tests to identify cognitive impairment in epidemiology and clinical research. 7 Telemed Telecare 2013;19(1):45-54. 